There is one aspect of the Ss' performance which is apparent in their mean $S^{D}$ rate and which does not appear so clearly in the test interval response rates. Mean response rates were usually slightly higher in the light-plus-silence $S^{D}$ than in the tone-plus-darkness $S^{D}$. The only exceptions to this statement were $S 4$ 's mean response rate during the last five pretest sessions and S 3's mean response rate during the last 10 test sessions. These data suggest that some type of stimulus dominance may be affecting the results of the experiment. However, it is not clear how such stimulus parameters would affect response summation.

These data do confirm Weiss's (1969) results in showing that response summation occurs even when the summation stimulus is less intense than either of the $\mathbf{S D}_{\mathbf{S}}$. They also show that the response summation effect can be maintained for prolonged periods and can be demonstrated using a response rate measure taken during the conditioning session rather than during extinction.

\section{REFERENCES}

MILLER, L. Compounding of pre-aversive stimuli. Journal of the Experimental Analysis of Behavior, 1969, 12, 293-299.

MILLER, L., \& ACKLEY, R. Summation of responding maintained by fixed interval schedules. Joumal of the Experimental Analysis of Behavior, 1970, 13, 199-203.

PAVLOV, I. P. (Translated by G. V. Anrep) Conditioned reflexes. London: Oxford University Press, 1927.

REBERG, D., \& BLACK, A. H. Compound testing of individually conditioned stimuli as an index of excitatory and inhibitory properties. Psychonomic Science, 1969, $17,30-31$.

VAN HOUTEN, R., O'LEARY, K. D., \& WEISS, S. J. Summation of conditioned suppression. Journal of the Experimental Analysis of Behavior, 1970, 13, 75-81.

WEISS, S. J. Summation of response strength instrumentally conditioned to stimuli in different sensory modalities. Journal of Experimental Psychology, $1964,68,151-155$.

WEISS, S. J. Attentional processes along a composite stimulus continuum during free-operant summation. Journal of Experimental Psychology, 1969, 82, 22-27.

WOL $F$ M. M. Some effects of combined $S D_{S}$, Journal of the Experimental Analysis of Behavior, $1963,6,343-347$.

\title{
Incubation of a passive avoidance response after frontal lesions in the rat*
}

\author{
BRUCE K. WURGEL† and MARLENE OSCAR-BERMAN \\ Boston Veterans Administration Hospital \\ and Boston University School of Medicine, Boston, Mass. 02130
}

Rats with lesions of prefrontal cortex were compared with sham operates and cortical controls on a one-trial stepdown passive-avoidance task. At training-test intervals of $5 \mathrm{sec}, 10 \mathrm{sec}$, or $24 \mathrm{~h}$, one-trial learning effects were observed. All groups showed an incubation effect, i.e., stepdown latencies increased after longer retest intervals. There were no differences between animals with prefrontal lesions and the sham controls, suggesting that frontals have normal short-term timing behavior.

Lesions of prefrontal cortex result in severely impaired pe. formance on

* We would like to thank Dr. "Villiam A. Wilson, Jr., and the Psychology Department of the University of Connecticut for allowing us the use of their facilities. We thank Drs. William I. Riddell and Nelson Butters for their helpful suggestions. Please address all reprint requests to Marlene Oscar-Berman, Psychology Service, Veterans Administration Hospital, 150 South Huntington Avenue, Boston, Mass. 02130. +Present address: Department of Anthropology, Unjersity of Cincinnati. Cincinnati, Ohio 45221 . delayed response and delayed alternation tasks in monkeys (see Pribram, Ahumada, Hartog, \& Ross, 1964) and in rats (Bourke, 1954). One interpretation of this deficit is that frontally damaged animals suffer from a loss of recent or immediate memory (Jacobsen, 1935). Consolidation theorists (Glickman, 1961; McGaugh, 1966; Pinel \& Cooper, 1966) have suggested that in one-trial passive-avoidance learning situations, incubation of the learned experience occurs during a time interval usually associated with immediate or short-term memory; they report a positive correlation between memory strength and training-test interval. The present study tests the effects of prefrontal lesions in rats upon immediate memory for footshock (FS) in a passive-avoidance situation. If the prefrontal cortex is important in incubation of the memory trace for the FS, removal of that cortical area should result in no change from the preshock stepdown latency when the retention interval falls within a short-term incubation period.

\section{SUBJECTS}

The Ss were 54 hooded rats of the Long-Evans strain. They ranged in age from 3 to 5 months at the start of the study. All Ss were divided randomly into three groups of 18 . The rats in the experimental (F) group received one-stage bilateral lesions of the prefrontal cortex (Fig. 1). Those in the cortical control (P) group had an equivalent amount of posterior (parietal) cortex bilaterally removed (Fig. 1). A group of sham operates (N) served as normal controls.

\section{APPARATUS}

The stepdown apparatus was identical to that described by Riddell $\&$ Herman (1968). It consisted of a $2 \times 2 \mathrm{ft}$ electric FS grid enclosed by four walls, $18 \mathrm{in.} \mathrm{high.} \mathrm{A} 6 \times 6$ in. stepdown platform was placed in one corner of the apparatus, and a clear 18-in. Plexiglas guillotine door enclosed the platform. A simple string harness was used to facilitate the replacement of $S$ onto the platform.

\section{PROCEDURE}

During the habituation phase of the experiment, each $S$ was given one stepdown trial a day without FS for 5 days. A trial began with $\mathbf{E}$ placing $S$ on the center of the raised platform. Stepdown latency (SDL), i.e., the time required for $S$ to place both front feet on the grid floor, was then measured. When all four feet were on the grid, the guillotine door was lowered to prevent S's return to the platform. The $S$ was allowed to remain on the grid floor for 5 sec before being returned
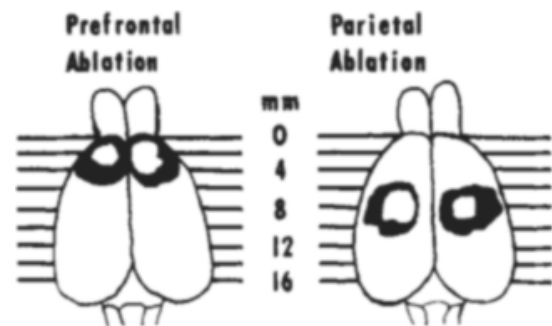

Fig. 1. Maximum (black) and minimum (central white) extents of cortical lesions. 
to the home cage. After the final habituation trial on the fifth day, median SDLs were determined for each $\mathrm{S}$. On the basis of latency scores, each of the groups ( $F, P$, and $N$ ) was further subdivided into three matched groups to be tested at different retention intervals for passive avoidance of the grid floor. The retention interval to be interposed between the training trial and the test trial for Ss in the matched groups was $5 \mathrm{sec}, 10 \mathrm{sec}$, or $24 \mathrm{~h}$. Eight Ss ( $2 \mathrm{Fs}, 3$ $\mathrm{Ps}$, and $3 \mathrm{Ns}$ ), with median SDLs exceeding $30 \mathrm{sec}$, were excluded from the experiment.

On the day following the last habituation trial, when S stepped from the platform, a $1-\mathrm{mA}$ FS was given through the grid floor for 2 sec. Upon termination of the FS, $S$ was returned to the platform via the string harness, and the guillotine door was lowered. The guillotine door was then raised $5 \mathrm{sec}$ or $10 \mathrm{sec}$ following the onset of the footshock, and E recorded SDLs. All Ss in the 24-h condition were returned to their cages after the FS and were tested for retention $24 \mathrm{~h}$ later. If on the test trial $S$ remained on the platform for $5 \mathrm{~min}$, the trial was terminated.

\section{RESULTS}

A series of Mann-Whitney $U$ tests was used for intergroup statistical comparisons, and the sign test (Siegel, 1956) was used for intragroup (repeated) comparisons. The effects of the different testing conditions are presented graphically in Fig. 2.

There were no significant differences between any of the groups' preshock latencies. After the administration of FS, latencies increased over time; the SDL on the retention trial was greater than the SDL on the training trials for all groups $(p<.05)$ except for the 5 -sec $P$ group. Differences between the 5 -sec and the 10 -sec conditions within the $\mathrm{N}$ group and within the $F$ group were not significant, but SDLs were significantly higher after $24 \mathrm{~h}$ than after $10 \mathrm{sec}(\mathrm{p}<.05)$ or after $5 \mathrm{sec}$ $(p<.05)$ for each of these two groups of Ss. Although at the 5-sec FS retention interval there was no difference between the $F$ and $N$ groups, the SDLs of Ns and Fs were significantly longer than those of the $P$ group $(\mathrm{p}<.01$ and $\mathrm{p}<.05$, respectively). The Ps showed significant differences between the $5-\mathrm{sec}$ and the $10-\mathrm{sec}$ conditions $(\mathrm{p}<.01)$ and between the $5+\mathrm{sec}$ and the $24-h$ conditions $(p<.01)$ however, there was no difference between the $10-\mathrm{sec}$ and the $24 \cdot \mathrm{h}$ conditions. At $10 \mathrm{sec}$ and at $24 \mathrm{~h}$, there were no significant differences among any of the groups.

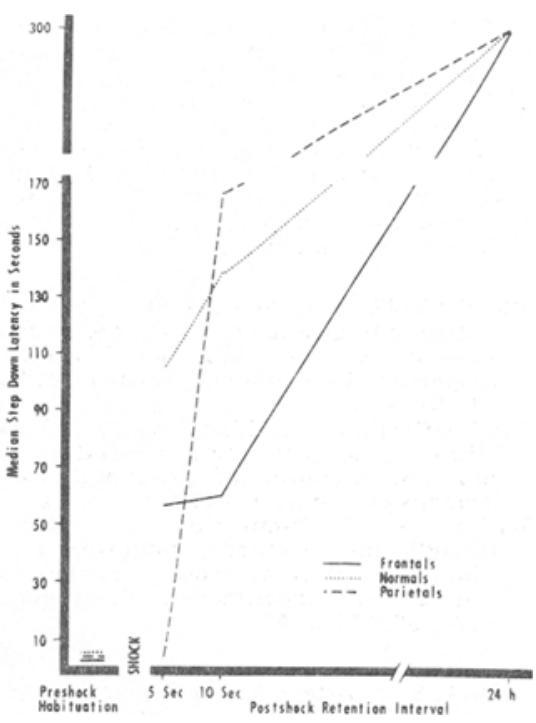

Fig. 2. Median stepdown latencies during preshock habituation training, and after each of the three postshock retention intervals $(5 \mathrm{sec}, 10 \mathrm{sec}$, or $24 \mathrm{~h}$ ).

In summary, the results indicate that the $N$ group and the $F$ group exhibited identical incubation trends: Latency increased as the interval between training and retention increased. The $P$ group differed from these groups at the shortest FS retention interval; no incubation effect was evident at 5 sec. Otherwise, in the 10-sec and 24-h conditions, the $\mathrm{P}$ group was similar to the $\mathrm{N}$ and $\mathrm{F}$ groups.

\section{DISCUSSION}

The results of the present study confirm the existence of an incubation effect as previously demonstrated in the normal rat, i.e., retention increases with an increase in the training-test interval (McGaugh, 1966; Pinel \& Cooper, 1966). This incubation effect has been considered indicative of the consolidation process of memory (McGaugh, 1966). Since consolidation was present and was increasing with each longer time interval tested, and since there were no significant differences between the normals and the frontals, this study indicates that rat frontal cortex is not necessary for normal incubation of an experience occurring during a time interval usually associated with short-term memory. Rather, the study complements the idea that frontals have normal timing behavior (Finan, 1939; Stamm, 1963; Thompson, 1964; Schmaltz \& Isaacson, 1968). In addition, since the reinforcement here was somesthetic (footshock), the study extends to the rat the finding that frontal animals can respond normally to somesthetic input (Oscar \& Wilson, 1966).

In the present study the posterior (parietal) cortical controls at the 5-sec training-test interval failed to exhibit the retention displayed by the $F$ and $N$ groups. This may be related to the fact that animals with lesions of parietal cortex exhibit a deficit in tactual ability (Wilson, 1957). An attenuation of sensitivity to tactual stimulation may explain the differences between the $P$ group and the other groups: Footshock was a weaker stimulus for the $P$ group, and therefore, consolidation took longer.

\section{REFERENCES}

BOURKE, W. T. The effects of frontal lobe damage upon habit reversal in the white rat. Journal of Comparative \& Physiological Psychology, 1954, 47, 277-282.

FINAN, J. L. Effects of frontal lobe lesions on temporally organized behavior in monkeys. Journal of Neurophysiology, $1939,2,208-226$.

GLICKMAN, S. E. Perseverative neural processes and consolidation of the memory trace. Psychological Bulletin, 1961, 3, 218-233.

JACOBSEN, C. F. Functions of the frontal association area in primates. Archives of Neurology \& Psychiatry, 1935, 33, 558-569.

McGAUGH, J. L. Time dependent processes in memory storage. Science, 1966,153 , $1351-1358$.

OSCAR, M., \& WILSON, M. Tactual and visual discrimination learning in monkeys with frontal lesions. Journal of Comparative \& Physiological Psychology, 1966,62, 108-114.

PINEL, J. P. J., \& COOPER, R. M. Incubation and its implications for the interpretation of the ECS gradient effect. Psychonomic Science, 1966, 63, 123-124.

PRIBRAM. K. H., AHUMADA, A.. HARTOG, J., \& ROSS, L. A progress report on the neurological processes disturbed by frontal lesions in primates. In J. M. Warren and $\mathrm{K}$ Akert (Eds.), The frontal granular cortex and behavior. New York: McGraw-Hill, 1964. Pp. 28-55.

RIDDELL, W. I., \& HERMAN, T. Incubation in one-trail passive avoidance learning: A cautionary note. Psychonomic Science, 1968, 12, 335-336. SCHMALTZ, L. W., \& ISAACSON, R. L. Effects of caudate and frontal lesions on retention and relearning of a DRL schedule. Journal of Comparative \& Physiological Psychology, 1968, 65, 343-348.

SIEGEL, S. Nonparametric statistics. New York: McGraw-Hill, 1956.

STAMM, J. Function of prefrontal cortex in timing behavior of monkeys. Experimental Neurology, 1963, 7, 87-97. THOMPSON, $R$ A note on cortical and subcortical injuries and avoidance learning by rats. In J. M. Warren and $K$. Akert (Eds.). The frontal granular cortex and behavior. New York: MeGraw-Hill, 1964. Pp. 16-27.

WILSON, M. Effects of circumscribed cortical lesions upon somesthetic and visual discrimination in the monkey. Journal of Comparative \& Physiological Psychology, 1957, 50, 630-635. 